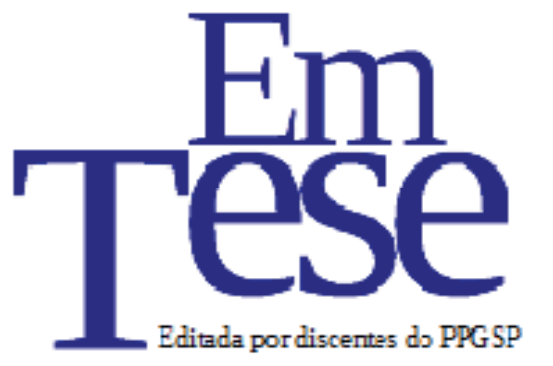

UFSC

PPG SP PROG RAMA DE

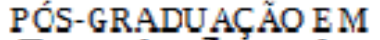

Sociologia

Política

\title{
Pobreza e alienação eleitoral em Moçambique ${ }^{1}$
}

\section{Acrisio Pereira Victorino ${ }^{2}$ Carlos Augusto da Silva Souza ${ }^{3}$}

Resumo: O presente artigo tem como objetivo investigar os fatores que tem possibilitado a expansão da alienação eleitoral nas eleições legislativas em Moçambique, de 1994 a 2014. A pesquisa parte da evidência de que há uma tendência de mudança no comportamento do eleitor, ao longo das eleições já realizadas em Moçambique. Neste sentido, procurou-se avaliar se a condição de pobreza estimula, retrai ou não afeta no nível de alienação eleitoral. A metodologia utilizada para a realização do estudo foi quantitativa, baseada nos dados eleitorais de 1994 a 2014, e em dados secundários que indicam o nível de pobreza no país. Os resultados da pesquisa indicam que a variação do comportamento do eleitorado moçambicano associado com os altos níveis de pobreza registrados no país.

Palavras-chave: Alienação eleitoral; Pobreza; Eleições legislativas.

\section{Poverty and alienation in Mozambique}

Abstract: This article has the objective of investigate the factors that have made possible the expansion of electoral alienation in the parliamentary elections in Mozambique, from 1994 to 2014. The research part of the evidence that there is a trend of change in voter behavior, throughout the elections already held in Mozambique. In this sense, we tried to assess whether the condition of poverty stimulates, retracts or does not affect the level of electoral alienation. The methodology used for the study was based on quantitative electoral data, 1994 to 2004, and in secondary data that indicate the level of poverty in the country. The survey results indicate that the change in the behavior of the Mozambican electorate associated with high levels of poverty in the country.

Key-words: Electoral alienation; Poverty; Legislative elections.

\footnotetext{
${ }^{1}$ Agradecemos ao professor dr. Rafael da Silva, da Universidade Estadual de Maringá, pelas relevantes indicações bibliográficas que ajudaram na construção deste artigo, à professora dra. Eugênia Rosa Cabral, do Programa de Pós-graduação em Ciência Política da Universidade Federal do Pará, pelas preciosas sugestões e à Cleide Patrícia De Sousa Fernandes pelas correções ao longo do trabalho.

${ }^{2}$ Graduado em Administração Pública pela Universidade Eduardo Mondlane. Mestrando em Ciência Política na Universidade Federal do Pará e bolsista da CAPES. E-mail: acrisio.victorino@gmail.com.

${ }^{3}$ Professor e coordenador no programa de Pós-graduação em Ciência Política da Universidade Federal do Pará UFPA. E-mail: carlossouza@ufpa.br.
} 


\section{Introdução}

Este trabalho apresenta como objetivo de investigação analisar o comportamento do eleitorado em Moçambique a partir dos componentes da chamada alienação eleitoral, visualizada pela literatura como aquela situação em que o eleitor se encontra apto a votar, mas por alguma razão prefere não comparecer ao local de votação, ou mesmo comparecendo, acaba anulando seu voto ou votando em branco. Em Moçambique, cujo sistema eleitoral adota o voto facultativo, as taxas de alienação eleitoral são bastante elevadas e existem poucos estudos que se lançaram numa tentativa de entender este fenômeno. Daí que nos basearemos nos estudos feitos no Brasil onde o voto é obrigatório e as urnas são eletrônicas, diferente do nosso caso de estudo em que ainda prevalece o uso das cédulas eleitorais.

É neste sentido que esta pesquisa se justifica, nela pretendemos evidenciar possíveis explicações sobre as elevadas taxas de alienação eleitoral ocorridas no período pósdemocratização, recorrendo aos indicadores de natureza socioeconômica como possíveis variáveis explicativas.

Os dados da pesquisa foram estabelecidos a partir das informações coletadas no site do Instituto Nacional de Estatística de Moçambique, relativas à taxa de pobreza ${ }^{4}$ agregado, que se constitui num indicador que procura medir a taxa de pobreza do país e regiões através de pesquisas periódicas intituladas de "Inquérito do Orçamento Familiar", baseado na renda total dos inquiridos. A partir destes indicadores e dos dados das taxas de alienação eleitoral (medidas pelas abstenções, votos brancos e nulos) foi possível associar estes indicadores.

A história política de Moçambique começa em 1975, com sua independência do regime colonialista. Entre 1975 e 1990 o país passou por períodos de intenso conflito derivado da guerra civil estabelecida entre duas forças políticas que procuravam, através da luta armada, assumir o controle do poder político: A Frente de Libertação de Moçambique (FRELIMO) e a Resistência nacional Moçambicana (RENAMO).

Moçambique no período pós-democratização realizou cinco eleições, tendo como o órgão responsável pela efetivação deste processo a Comissão Nacional de Eleições (CNE) e o Secretariado Técnico de Administração Eleitoral (STAE). Ao longo dessas cinco eleições consecutivas o partido Frente de Libertação de Moçambique (FRELIMO) saiu-se vencedor em todas elas, tanto para o governo central, quanto para a composição do poder legislativo,

\footnotetext{
${ }^{4}$ A pobreza encontra-se relacionada com a falta de rendimentos (dinheiro ou espécie) necessários para a satisfação das necessidades básicas. Sendo que esta definição monetária não abrange outras vertentes da pobreza, foi alargado o conceito para abarcar aspectos como falta de acesso à educação, saúde, água e saneamento, bem como o isolamento, exclusão social, falta de poder e vulnerabilidade.
} 
onde conseguiu maioria dos assentos no parlamento Moçambicano. Nas três últimas eleições, entretanto, o eleitor tem demonstrado claramente sua rejeição a este partido, expresso no aumento do absenteísmo eleitoral e nas elevadas taxas de votos brancos e nulos verificadas a partir de 2004, o que tem comprometido a legitimidade dos eleitos frente à representação social que o sistema democrático deveria construir. Importa referir que em Moçambique o voto é facultativo, com um sistema de governo semipresidencialista, apesar de existência do vários partidos, há uma predominância de um sistema bipartidário, com um partido dominante que é a FRELIMO.

Este fenômeno da alienação eleitoral tem levado a Comissão Nacional de Eleições, bem como o Secretariado Técnico de Administração Eleitoral, a promoverem campanhas com vista a sensibilizar o eleitor a participar mais ativamente dos pleitos eleitorais, por meio do exercício consciente do voto, contudo esta estratégia parece não ter surtido efeito, pois o fenômeno da alienação eleitoral tem se mantido constante nas diversas eleições ocorridas a partir de então.

Partimos da ideia que existe uma associação entre a alta taxa de pobreza e alienação eleitoral nas eleições legislativas. Apesar da alienação eleitoral, em seu conjunto, ser um conceito extremamente polêmico entre os estudiosos, pois concentram indicadores diversos, no caso, abstenções, voto brancos e nulos, que nem sempre podem ser medidos de forma precisa, são principalmente as abstenções que mascaram o real significado deste indicador, uma vez que o não comparecimento do eleitor às urnas pode nem sempre estar relacionado a uma indiferença com o processo eleitoral. A literatura tem indicado que a ausência do eleitor às urnas pode dar-se por fatores alheios a sua vontade como: viagens, doenças ou mesmo condições logísticas e ecológicas presentes em cada sistema eleitoral particular. De qualquer forma, optamos por incluir as três variáveis indicativas da alienação (abstenções, votos brancos e nulos) devido à dificuldade de desagregação dos dados presentes nas instituições eleitorais moçambicanas e também pela carência de estudos sobre as diversas dimensões do sistema eleitoral de Moçambique.

Do ponto de vista teórico, utilizamos a teoria da escolha racional para entender a relação entre alienação eleitoral e pobreza. Utilizamos uma metodologia quantitativa na análise, por entender que os dados disponíveis permitem que sejam feitas algumas inferências, ainda que estas possam ser mais bem aplicadas mediante aprofundamento da investigação, em termos qualitativos. A pesquisa foi desenvolvida com uma base de dados secundários, isto é, dados oficiais sobre os indicadores socioeconômico, disponível nos sites do Ministério de 
Planificação e Desenvolvimento (MPD); Instituto Nacional de Estatística (INE); e Programa das Nações Unidas para o Desenvolvimento (PNUD). Utilizamos também os resultados eleitorais agregados, disponíveis no órgão de gestão eleitoral intitulado Secretariado Técnico de Administração Eleitoral (STAE) e Comissão Nacional de Eleições (CNE). Nestes termos, fizemos associação da medida de produtividade qualitativa e quantitativa, que foram os resultados eleitorais de Moçambique e as condições socioeconômicas relacionadas com a avaliação das taxas de pobreza do país.

A pesquisa teve o cunho analítico pelo fato de ter usado a pesquisa bibliográfica do debate sobre alienação eleitoral desenvolvido por Santos (1987); Lima (1990); Nicolau (2002a, 2003b); Figueiredo (2008); Borba (2008) e Ramos(2004a, 2006b, 2009c). É importante frisar que estes autores têm como objeto de estudo uma realidade onde o voto é obrigatório, sendo que neste estudo focaremos numa realidade onde o voto é facultativo, com vista a testar a teoria sobre alienação eleitoral. A análise dos dados baseou-se em uma modelagem estatística e na construção de tabelas e gráficos, que permitiu a interpretação, criando correlações. Sendo assim, este trabalho possui a seguinte estrutura: além desta introdução, a segunda parte é reservada a um breve debate sobre o fenômeno "alienação eleitoral". Na terceira parte fizemos uma breve apresentação sobre a evolução da participação eleitoral e na quarta parte são apresentados e analisados os dados empíricos sobre a associação existente entre pobreza e alienação eleitoral em Moçambique.

\section{O debate sobre alienação eleitoral}

Estudos demonstram que nas democracias representativas o voto é uma condição sine qua non da participação política. Este pressuposto assenta-se na ideia de que, primeiro, a participação eleitoral é uma das formas de participação que envolva um maior número de cidadãos em regimes democráticos e, segundo, que esta é uma das formas de participação exercida com frequência, numa rotina que confere um mandato representativo que varia de quatro a cinco anos, dependendo de cada país (LEWIS BECK, 1988). Entretanto, apesar da ideia de que os regimes democráticos necessitam do consentimento do eleitor na conferência do mandato representativo, a literatura tem demonstrado que tem havido um crescimento do comportamento alienado do eleitor ativo em vários países, a exemplo do que se vê em Moçambique, onde este fenômeno tem oscilado desde 1994 até as últimas eleições de 2014. 
Para Ramos (2004a, 2006b), as democracias representativas contemporâneas são caracterizadas por eleições frequentes dos seus representantes, onde o processo eleitoral possui dois distintos resultados preliminares, tais como: o total de votos válidos e o somatório de votos brancos, nulos e abstenções, designado por alienação eleitoral ${ }^{5}$. Portanto, nem todos os eleitores ativos participam nas escolhas dos seus representantes nas eleições legislativas, ou seja, existe uma tendência atualmente do eleitorado apto a votar alienar seu voto, seja por fatores, políticos, ecológicos ou socioeconômicos. Nota-se, especialmente desde a década de 1990, que o nível de abstenção eleitoral, bem como os votos nulos e brancos, nas democracias representativas tem atingido números alarmantes, quer na Europa, Estados Unidos, América Latina ou África ${ }^{6}$.

Sendo o voto em democracias representativas uma condição fundamental da participação eleitoral e a evolução da não participação eleitoral, materializada nas taxas de abstenção e a indiferença eleitoral materializada nos votos brancos e nulos, denominado por alienação eleitoral ${ }^{7}$, este fenômeno é visto no cenário da democracia representativa como um problema para legitimidade dos representantes e das instituições democráticas (COSTA, 2007); (FILGUEIRAS, 2008). Entretanto, a alienação eleitoral pode ser visualizada como um elemento crucial da ilegitimidade da democracia representativa, pois na medida em que somente uma minoria exerce efetivamente seu poder cívico, isto compromete o ideal de governo da maioria que o ideal democrático procura estabelecer. No contexto moçambicano, este fenômeno começa ser mais evidente em 2004, onde alienação eleitoral foi de $73 \%$, ou seja, somente $37 \%$ participaram de forma efetiva na escolha dos representantes.

No que concerne à participação eleitoral na vertente da alienação eleitoral, se manifesta através de duas modalidades de voto: votos brancos e nulos. Existe uma discordância em relação aos teóricos especializados sobre seu significado. De um lado, temos autores favoráveis à tese dos votos brancos e nulos como expressão de protesto e de descontentamento do eleitor (SANTOS, 1987); (BORBA, 2009). De outro, há pesquisadores que defendem que esses votos são reflexos da baixa sofisticação política do eleitorado, que se materializaria, em parte, nas dificuldades cognitivas para operar de maneira correta a urna eletrônica ou cédulas eleitorais (NICOLAU, 2002a, 2003b).

\footnotetext{
${ }^{5}$ Por um lado a alienação eleitoral pode ser resultado de falhas mecânicas (como a não familiaridade com o boletim de votos por parte dos indivíduos que exercem seu voto pela primeira vez, à posição do partido no boletim de voto, entre outras falhas), por outro lado incapacidade de acesso e a distância entre a residência e o local de votação e o clima, este conjunto de possibilidades não representam a escolhas, mas sim restrições.

${ }^{6}$ Ver em Justel (1995); Perea (1999); Lane e Ersson (1987); Freire (2000); Magalhães (2002); Wattenberg (1999a, 2000b) e Brito (2007) sobre dados de vários países.

${ }^{7}$ Ver em Santos (1987).
} 
O nível da não participação eleitoral tem se tornado um fenômeno universal, atingindo maiores proporções em democracias representativas, onde o voto é facultativo ${ }^{8}$. Porém, apesar da sua magnitude, não há consenso na literatura em relação ao significado deste fenômeno. Há duas explicações possíveis para este fenômeno: 1- a literatura sustenta a necessidade de determinados índices de não participação eleitoral para a estabilidade do regime democrático, conforme Almond e Verba (1963) e Lipset (1967), 2- olham o fenômeno com preocupação, apontando indícios de desgaste social, apatia e desinteresse pela política (VITULLO, 2001a, 2002b); (KINZO, 2005).

Podemos afastar o preconceito existente no termo alienação eleitoral e mencionar o termo não participação, que envolve aqueles que não participaram diretamente da escolha de seus representantes políticos, uma vez que estão inseridos no contingente de eleitores aptos a participar do processo de votação, tido como abstenção eleitoral. A abstenção aparece em muitos estudos como uma variável de menor magnitude e tende a crescer em países onde o voto é facultativo em detrimento dos países onde o voto é obrigatório como é o caso de Moçambique. Neste sentido, a abstenção inclui não apenas os eleitores inscritos, mas sim todos os cidadãos e cidadãs que estão aptos a participar nos pleitos eleitorais e não o fazem. Em situações onde o voto é facultativo, este eleitorado ativo tende decidir a votar ou não dependendo das suas condições socioeconômicas, ecológicas e políticas.

Teóricos como Santos (1987) e Figueiredo (1991) afirmam que a não participação eleitoral é, por um lado, uma consequência mental ou cultural de qualquer sociedade e, por outro lado, é eminentemente uma ação técnica, onde as pessoas participam quando e se as suas ações são compreendidas por elas mesmas, como sendo capazes de produzir resultados esperados. Ou seja, os cidadãos só participam em pleitos eleitorais quando acreditam que suas ações serão efetivadas. Em relação a este fenômeno, Lima (1990) faz menção a ideia de "comportamento eleitoral alienado", como sendo aqueles eleitores que compreendem e vivem de forma consciente o cenário político e que por algum motivo decidem não participar no âmbito da escolha dos seus representantes.

Esta suposição em torno da alienação ${ }^{9}$ eleitoral está centrada na arena política, naquelas situações onde a motivação dos interesses e valores é muito pratica, ou seja, está relacionada à ação. Os resultados políticos são baseados por algum valor, onde as consequências dos atos nem sempre condizem com as intenções dos agentes (RAMOS,

\footnotetext{
${ }^{8}$ Uma visão, tanto dos debates internacionais, quanto aos dados sobre alienação eleitoral em Moçambique veja em Terenciano (2016); Brito (2007); Silva (2014); Costa (2006); Santos (1987) e Ramos (2004a, 2006b, 2009c). ${ }^{9}$ O termo alienação eleitoral em Ramos (2004a, 2006b, 2004c) é denominado por "alheamento eleitoral"
} 
2004a, 2006b, 2009c). Para Ramos (2004a, 2006b), esta segunda suposição resulta do caráter prático do político: tanto os votos válidos depositados, quanto à alienação eleitoral são comportamento dos eleitores. E por último, a terceira suposição, centra-se na ideia que a intenção e os resultados não são opostos.

No entanto, apesar das motivações que cada fenômeno constitui, o alienamento eleitoral seja oposto entre si (votos nulos genericamente são relacionados a protesto, votos em brancos, ao desinteresse e abstenções, a rejeição aos candidatos ou ao comodismo), o impacto causado pelo comportamento eleitoral sob o distanciamento da legitimidade do sistema representativo é idêntico para as três formas avançadas de ação (RAMOS, 2004a, 2006b).

Em torno deste debate sobre votos válidos e alienação eleitoral, podemos aferir que o voto válido refere-se à efetiva escolha dos representantes pelos eleitores, e a alienação eleitoral por sua vez significa a falta da escolha dos representantes, sendo que toda ação social é sujeita a uma intenção, então se torna fundamental observar o comportamento do eleitorado alienado (votação por meio de voto branco, nulo e abstenção) ligado ao comportamento político (apatia e protesto) e, por conseguinte às possíveis motivações (alienação, satisfação ou insatisfação política) que são dimensões subjetivas do processo político (RAMOS, 2004b, 2006c).

Entretanto, algumas características são importantes serem avançadas para explicar a ideia de alienação eleitoral no contexto moçambicano: 1- os votos em branco e nulos representam a associação existente entre a baixa sofisticação política e o baixo índice de escolaridade segundo Santos (1987), Ramos (2004a), Figueiredo (1991), Lima (1990); 2abstenção, que é a não participação do eleitor ativo no processo eleitoral, que está associada ao fator da pobreza, principalmente aos eleitores de baixa renda (SANTOS, 1987) e (BRITO, 1995).

Neste contexto, o voto em branco e o voto nulo apresentam uma não escolha. Ressaltese que a doutrina costuma distinguir entre os eleitores que votam nulo, aqueles que o fazem deliberadamente e os que o fazem por ignorância ou erro, sem consciência da impropriedade de sua escolha (RAMOS, 2006b, 2004c). Em relação à anulação intencional de votos, agrupase um determinado comportamento de insatisfação política do eleitor ativo em relação aos seus representantes. Por último, a abstenção se determina por um não comparecimento do eleitor ativo e escrito nas urnas no dia da votação, e é uma clara demonstração de apatia ou protesto eleitoral em relação às instituições democráticas, bem como a não identificação do eleitorado com o candidato ou partido. 
As primeiras abordagens sobre esse fenômeno centravam-se principalmente no procedimento de aglutinação em um único fenômeno, a alienação de distintos comportamentos do eleitorado (os votos brancos, nulos e as abstenções), para os quais se estabeleceu uma mesma base causal (LIMA JÚNIOR, 1990). Segundo o autor, pode-se objetivar, no entanto, que a interpretação do comportamento eleitoral alienado, na medida em que agrega manifestações eleitorais diferentes, esteja equivocada do ponto de vista dos fatores determinantes da alienação. Ou, simplesmente: o que leva o eleitor a se abster não é exatamente o que leva o eleitor a votar em branco ou a anular o voto (LIMA JÚNIOR, 1990).

O estudo de Nicolau (2002a, 2003b) problematiza os votos brancos e nulos, e defende a tese de que, principalmente os votos nulos, devem ser compreendidos como resultado da baixa sofisticação do eleitorado, especialmente no aspecto da escolaridade. Para o autor, isso fica evidente ao comparar as taxas de votos nulos antes e depois da instauração da urna eletrônica, quando se verifica uma queda substancial dos votos brancos e nulos. No contexto moçambicano, onde o nível de população não alfabetizada e vivendo na pobreza ainda é muito elevado, sendo que a maior parte do eleitorado se encontra vivendo sob esses problemas, pode ser um fator importante para perceber o crescimento da alienação eleitoral, onde a dificuldade de manusear as cédulas eleitorais faz com que alguns votos sejam anulados por erro na escrita do nome do candidato ou do partido.

De qualquer forma a alienação eleitoral pode ser interpretada a partir de seus diversos significados. De um lado, entende-se como a manifestação de um processo de eleições, onde os indivíduos, aptos e inscritos para exercer seu poder de escolha dos representantes políticos não o fazem. Por outro lado entende-se, também como a ausência de uma escolha por indivíduos que, aptos a votarem, por variadas razões, não o fazem, ou seja, ou se abstêm ou vota nulo ou em branco (COSTA, 2007); (RAMOS, 2009c). Contudo, podemos afirmar que os autores alegam que as variáveis ligadas a idade, renda e condições ecológicas estão diretamente ligadas a abstenção eleitoral, enquanto que, a escolarização, as questões técnicas e de regras institucionais estão ligadas a participação materializada através do voto branco e nulo.

O que nenhum dos trabalhos acima ostentou como variável de análise são as condições socioeconômicas e de que forma esta pode influenciar na não participação, bem como na participação materializada nos votos brancos e nulos. É notória uma expressiva literatura internacional sobre o chamado "voto econômico", com autores tais como Kiewiet (1983), Lewis Beck (1988), Kinder, Adams e Gronke (1989), Duch (2001) e seu impacto 
principalmente no plano do comparecimento eleitoral, em obras de Downs (1999) e Aldrich (1993). Tais análises ainda não foram devidamente incorporadas ao estudo do tema da alienação eleitoral em Moçambique.

Key Junior (1966) explica que os estudos sobre as teorias do voto racional, partem de uma premissa de satisfação econômica para assegurar legitimidade ao governante. Nesta interpretação, se o crescimento econômico vai bem, os representantes ganham os votos; em contrapartida, se o crescimento econômico vai mal, os indivíduos podem alienar seu voto ou votar em novos representantes. Esta tentativa teórica e epistemológica de reduzir o eleitor a um mero juiz que busca punir e recompensar seus representantes é uma forma quase frágil de analisar o comportamento político e eleitoral (FIGUEIREDO, 2008). Contudo, a partir desta lógica, é possível associar o exercício do voto, não o mero sentido julgador, mas como uma ação que pretende ser instrumental, ou estratégica do ponto de vista do eleitor.

Um indivíduo racional, do ponto de vista de Downs, se comporta da seguinte forma:

[...] Ele sempre pode tomar uma decisão quando confrontado com uma série de alternativas; Ele classifica todas as alternativas na ordem de sua preferência; Seu ranking de preferência é transitivo; Ele sempre escolhe entre todas as alternativas possíveis, aquela que fica em primeiro lugar no ranking ordenado de preferência; Ele sempre toma a mesma decisão quando é confrontado com as mesmas alternativas [...] (DOWNS, 1999, p: 28).

Mais uma vez o elemento economia é um vetor importante para explicar o não comparecimento eleitoral (MONROE, 1979); (KIEWIET, 1983); (KRAMER, GOODMAN, 1975). Desta forma, podemos inferir que em uma sociedade onde o voto é facultativo, as pessoas tendem a recorrer à alienação ${ }^{10}$, dependendo das condições materiais de vida, como é o caso da escolaridade, pobreza, índice de satisfação com o governo, que são indicadores que podem influenciar na sua capacidade de escolha ou de participar politicamente e eleitoralmente do processo de legitimação de seus representantes.

Neste contexto, todos os que podem tomar decisões (incluindo partidos políticos, grupos de interesse e governos), presume-se que possuem as mesmas qualidades de escolha, isto é, agem racionalmente. Portanto, um homem racional, sempre opta pela alternativa que

\footnotetext{
${ }^{10}$ Seria basicamente o contrário da síndrome de alienação política que foi apresentado por Figueiredo, citando Robert Lane (1962, p. 162). Que postulam as três síndromes de alienação? Postulam a ideia segunda qual, o indivíduo ou eleitor perante o cenário político, assume que: 1 - eu sou objeto e não sujeito da vida política, eu não tenho influencia e não partido, porque politicamente falo em voz passiva; 2- o governo não cuida e nem administra no meu interesse; 3- Eu não aprovo o processo de tomada de decisão, as regras são injustas, ilegítimas. Destacamos com maior ênfase a segunda síndrome, que mais se enquadra na ideia de que, se a economia está bem, então não necessito participar, e se há variações na economia, então os eleitores, sobretudo os racionais, como estamos vindo enfatizar, votam para destituir o governo.
} 
lhe proporciona maior utilidade, ou seja, consideramos que a sua decisão apresenta os pressupostos racionais, como a informação suficiente, previsibilidade, custo e benefício voltado para o jogo ótimo (DOWNS, 1999). Assim, um eleitor ao agir racionalmente leva em consideração os benefícios esperados, resultantes da atividade governamental para escolher o candidato ou partido que lhe trará a maior utilidade ou opta por alienar seu voto.

A decisão de participar de uma eleição traz para o eleitor a responsabilidade da escolha, sendo que na teoria da escolha racional esta decisão é pautada por um cálculo para avaliar os custos referentes ao deslocamento e as possíveis vantagens que podem ser obtidas caso decida votar. Se tais benefícios esperados superarem os custos, o eleitor participa da eleição (DOWNS, 1999). Mas também é possível associar a teoria do voto positivo, na medida em que os benefícios extraídos do ato de votar consigam compensar seu custo de votação, isto é, o eleitor tende a participar de forma constante quando suas ações são realizadas de alguma forma.

\section{Um olhar sobre as abstenções, votos brancos, nulos e alienação eleitoral em Moçambique}

Em 1990, após quase 16 anos de guerra civil é assinado um Acordo Geral de Paz ${ }^{11}$ entre as duas principais forças políticas, o que leva a Promulgação de uma nova Constituição que instaura o regime multipartidário que possibilitou o surgimento de novos partidos políticos e a realização das primeiras eleições multipartidárias em 1994. Desde então, foram realizadas nove eleições ${ }^{12}$, sendo cinco eleições presidenciais conjugadas com eleições legislativas e quatro eleições municipais.

Nas primeiras eleições legislativas concorreram 14 partidos $^{13}$, sendo que apenas três obtiveram votos suficientes para ultrapassar a clausula de barreira imposta pela legislação, para preencher os 250 assentos na Assembleia da República. Das cadeiras disponibilizadas, 129 foram ocupados por deputados eleitos pela FRELIMO (Frente de Libertação de Moçambique), 112 pela RENAMO (Resistência Nacional de Moçambique) e nove foram

\footnotetext{
${ }^{11}$ O Acordo Geral de Paz foi assinado em Roma em 4 de outubro de 1992, entre o partido-Estado (FRELIMO) e a RENAMO, que era o movimento de resistência, considerada como desestabilizador do país, que colocou o fim da guerra civil em Moçambique de 1976-1992.

${ }^{12}$ As eleições presidenciais e legislativas foram realizadas nos seguintes anos: 1994, 1999, 2004, 2009 e 2014 ; as municipais em: 1998, 2003, 2008 e 2013.

${ }^{13}$ Ver em Brito (1995); Terenciano e Sousa (2016).
} 
ocupados pela UD (União Democrática de Moçambique) ${ }^{14}$, os 11 partidos restantes alcançaram conjuntamente $12,7 \%$ do total dos votos, sem que nenhum tenha alcançado a cláusula de barreira de $5 \%$ exigida pela lei eleitoral ${ }^{15}$ oriunda do Acordo Geral de Paz, no seu Protocolo III. Portanto, desde as eleições de 1994 é possível notar uma evolução e oscilação em torno das abstenções, votos nulos e brancos têm sido constante como se pode observar na Tabela 1:

Tabela 1 - Abstenção, votos brancos, nulos e alienação eleitoral nas eleições legislativas em Moçambique em \%: $1994-2014^{16}$

\begin{tabular}{c|c|c|c|c}
\hline Anos & Abstenção & Votos brancos & Votos nulos & Alienação eleitoral \\
\hline 1994 & $13,0 \%$ & $3,0 \%$ & $7,0 \%$ & $23,0 \%$ \\
\hline 1999 & $30,0 \%$ & $11,0 \%$ & $5,0 \%$ & $46,0 \%$ \\
\hline 2004 & $63,0 \%$ & $5,0 \%$ & $5,0 \%$ & $73,0 \%$ \\
\hline 2009 & $56,0 \%$ & $8,0 \%$ & $8,0 \%$ & $72,0 \%$ \\
\hline 2014 & $52,0 \%$ & $8,0 \%$ & $2,0 \%$ & $62,0 \%$ \\
\hline
\end{tabular}

Fonte: CNE. Elaborado pelo autor (2016)

Como se pode observar na Tabela 1, entre 1994 e 2004, houve um crescimento acentuado na taxa de alienação eleitoral, principalmente a abstenção eleitoral, passando de $13 \%$ em 1994, para 30\% em 1999 e $63 \%$ em 2004 e reduzindo para 56\% e 52\% em 2009 e 2014 respectivamente.

A explicação para essa redução no índice de abstenção eleitoral nas últimas duas últimas eleições está vinculada ao fato de que, em 2007, houve um recadastramento eleitoral e muitos eleitores foram eliminados do sistema por diversos motivos: em primeiro lugar, os cadastros daqueles que haviam falecido foram cancelados; em segundo, os idosos que já não tinham condições de participar nas eleições também foram excluídos; e, terceiro, os eleitores que mudaram de residência e que teriam duplo cadastro foram regularizados. Todas estas ações possibilitaram um maior controle por parte da Comissão Nacional de Eleições sobre os reais eleitores inscritos e reduzindo deste modo à possibilidade de um aumento artificial de total de eleitores aptos a votar.

\footnotetext{
${ }^{14}$ União Democrática de Moçambique, que foi uma coligação que teve em voga se juntar entre partidos pequenos para alcançar a clausula de barreira. Ver em Terenciano e Souza (2016).

${ }^{15}$ Ver a legislação eleitoral de 1994.

${ }^{16}$ Números de eleitores escritos em: 1994 - 6.148.842; $1999-7.099 .105 ; 2004-9.142 .151 ; 2009-9.890 .655$ e 2014 - 10. 964.377.
} 


\section{Evolução da participação eleitoral nas eleições legislativas em Moçambique}

Autores como Nicolau (2002a, 2003b), Brito (2006), Figueiredo (1991), Filgueiras (2008) e Mazula (1995a, 2006b) argumentaram que os diferentes tipos de sistemas políticopartidário impactam na maior ou menor participação eleitoral. Entre os componentes mais significativos que influenciam na participação estão as regras eleitorais, bem como o regime de voto (obrigatório ou facultativo) existente em cada país. Para alguns autores, os regimes de voto facultativo tendem a reduzir o nível de participação eleitoral ao longo dos anos, mas existem estudos que também mostram que em países onde o voto é obrigatório também há essa tendência de redução da participação ao longo do processo eleitoral.

Tendo em vista que nossa análise é baseada nos resultados das ações não participativas agrupadas em três categorias (votos em branco, votos nulos e abstenções), que podem se dar por diferentes motivos, a alienação eleitoral precisa ser contextualizada em situações empíricas específicas para que sua explicação se torne clara de acordo com o cenário que se pretende analisar.

No contexto moçambicano, onde o regime de voto é facultativo, é visível essa tendência decrescente e contínua da participação eleitoral ao longo das eleições, onde podemos afirmar que o número de participação eleitoral, desde 2004, tem sido baixo em relação a não participação eleitoral. Isto quer dizer que há um decréscimo nos níveis de participação eleitoral em Moçambique em uma linha oscilatória, conforme observaremos no Gráfico 1:

Gráfico 1: Índice relativo a participação eleitoral nas eleições legislativas, em Moçambique, entre 1994 a 2014

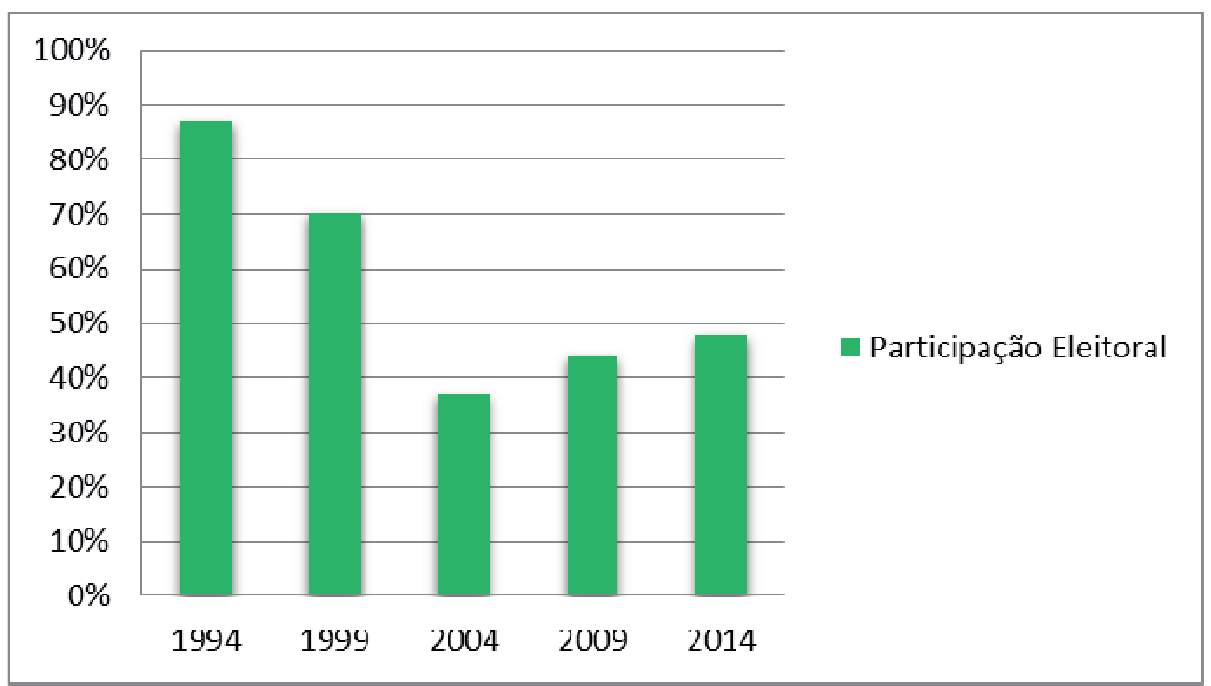


As dinâmicas da participação eleitoral em Moçambique são adversas e cada pleito eleitoral teve variações em termos dos percentuais de participação. Ora, nas eleições fundadoras de 1994, que instituíam a democracia multipartidária, a participação dos eleitores inscritos foi de $87 \%$, e a abstenção eleitoral situou-se em torno de $13 \%$. Esta tendência se manteve até as segundas eleições de 1999, onde houve uma participação de $70 \%$ dos potenciais eleitores, com a abstenção eleitoral a situar-se em 30\%. Alguns estudos desenvolvidos por Mazula (1995), Brito (2005), Sitoe (2006) e Nuvunga (2010), afirmam que essa tendência de redução no nível de participação deveu-se a vários fatores. De um lado, nas eleições de 1994 e 1999 o voto significava a reafirmação da paz, ou seja, o desejo coletivo de pôr um fim definitivo a guerra que assolou Moçambique por cerca de 15 anos, e, por outro lado, as pessoas foram movidas pela vontade de exercer seu poder de voto pela primeira vez. É válido destacar que o trabalho levado a cabo pelas instituições nacionais e internacionais no âmbito da educação cívica ${ }^{17}$ foi fundamental para essa tendência (MAZULA, 1995); (MAIA, 1995); (NAMBURETE, 1995).

Essa tendência de maior nível de participação foi interrompida a partir de 2004, onde se assiste o declínio da participação eleitoral que atingiu apenas $37 \%$ dos potenciais eleitores, tendo a abstenção eleitoral chegado a atingir $73 \%$ do total de eleitores do país. Isso mostra, por um lado, que as pessoas se fizeram presente no processo de registro eleitoral, mas não exerceram seu poder cívico de legitimação dos governantes.

Autores como Brito (op. cit) e Nuvunga (op. cit) advogam que os declínios na participação eleitoral nas eleições de 2004 estão ligados a dois pressupostos conjunturais. Por um lado, a eleição de 2004 ocorreu num cenário de chuvas intensas ao longo do todo país o que limitou a capacidade de participação do eleitorado. Por outro lado, a não atualização dos cadastros eleitorais fez com que existisse a duplicação do número de eleitores ativos em diversas regiões o que superestimou o quantitativo de eleitores realmente aptos a votar.

Em relação ao nível de participação nas eleições de 2009 e 2014, se nota um crescimento mais ou menos significativo em relação às eleições de 2004, onde o nível de participação foi de $44 \%$ e $48 \%$ respectivamente. Neste contexto, se verifica que a abstenção ainda continua num nível acentuado, ou seja, a participação materializada nos votos validos,

\footnotetext{
${ }^{17}$ Por um lado, a CNE disponibilizou uma equipa de 1.600 agentes de educação cívica, por outro lado, as diversas confissões religiosas e ONG's também criaram equipes de agentes de educação cívica, que trabalharam em paralelo. Ver Mazula (1995).
} 
nulos e brancos ainda continua inferior aos 50\%, sendo que em 2009 e 2014 a abstenção se situou em $56 \%$ e $52 \%$ respectivamente. Consideramos que essa redução insignificante das abstenções nas últimas eleições, pode ser explicada pelo fato de que em 2007, ocorreu novamente um registro eleitoral de raiz, o que possibilitou a eliminação de cadastros duplos bem como de eleitores que já haviam perdido a vida e os idosos que já não tinham condições de exercer seu ato cívico, possibilitando assim a redução da abstenção eleitoral, vis-à-vis aumento da participação eleitoral.

\section{Evolução da alienação eleitoral nas eleições legislativas em Moçambique}

Desde as primeiras eleições legislativas de 1994, há uma indicação de redução da participação eleitoral em Moçambique, onde o nível de abstenção, votos em branco e nulos têm crescido de forma regular. Este crescimento, de certa forma revela um desinteresse dos cidadãos em relação ao sistema político, que também pode ser um sintoma de crise do sistema democrático representativo (BRITO, 2010).

De acordo com Lewis Beck (1988) e Kinder, Adams e Gronke (1989), existe uma tendência generalizada em países onde o voto não é obrigatório, de ocorrer redução da participação popular em pleitos eleitorais ao longo do tempo. Na Europa, por exemplo, por volta da década de quarenta, a participação rondava em torno dos 86\%, apresentando decréscimo em torno de $78 \%$ a $80 \%$ nos anos 1990. Desde então vêem descendo de eleição a eleição e mais concretamente nos anos 2000 (LEWIS BECK, 1988); (KINDER, ADAMS E GRONKE, 1989). Para o caso de Moçambique, onde o voto é facultativo, a participação eleitoral foi de $87 \%$ em 1994, descendo para $70 \%$ em 1999, passando para $37 \%$ em 2004, sendo que em 2009 e 2014 a participação eleitoral se situou em 44\% e 48\% respectivamente, podemos assim dizer que ao longo das eleições já realizadas, o nível de alienação eleitoral tem oscilado de forma bastante significativa ${ }^{18}$.

O fenômeno da alienação eleitoral é notável nas eleições moçambicanas pósdemocratização, com um percentual de 23\% em 1994, em 1999 tendo ocorrido o dobro do percentual de 1994 em relação à alienação eleitoral, isto é 46\%, passando para $73 \%$ e 72\% nos anos 2004 e 2009 respectivamente, e em 2014 tendo se fixado em 62\%, como vemos no Gráfico 2:

\footnotetext{
${ }^{18}$ De acordo com os dados da Comissão Nacional de Eleições as taxas de abstenção, votos brancos e nulos nas eleições legislativas em Moçambique foram de: $1994-13 \%, 3 \%$ e 7\%; 1999-30\%, 11\% e 5\%; 2004-63\%, 5\% e $5 \% ; 2009-56 \%, 8 \%$ e $8 \%$ e por fim $2014-52 \%, 8 \%$ e $2 \%$ respectivamente.
} 
Gráfico 2: Participação relativa da alienação eleitoral nas eleições legislativas em Moçambique entre 1994 e $2014^{19}$

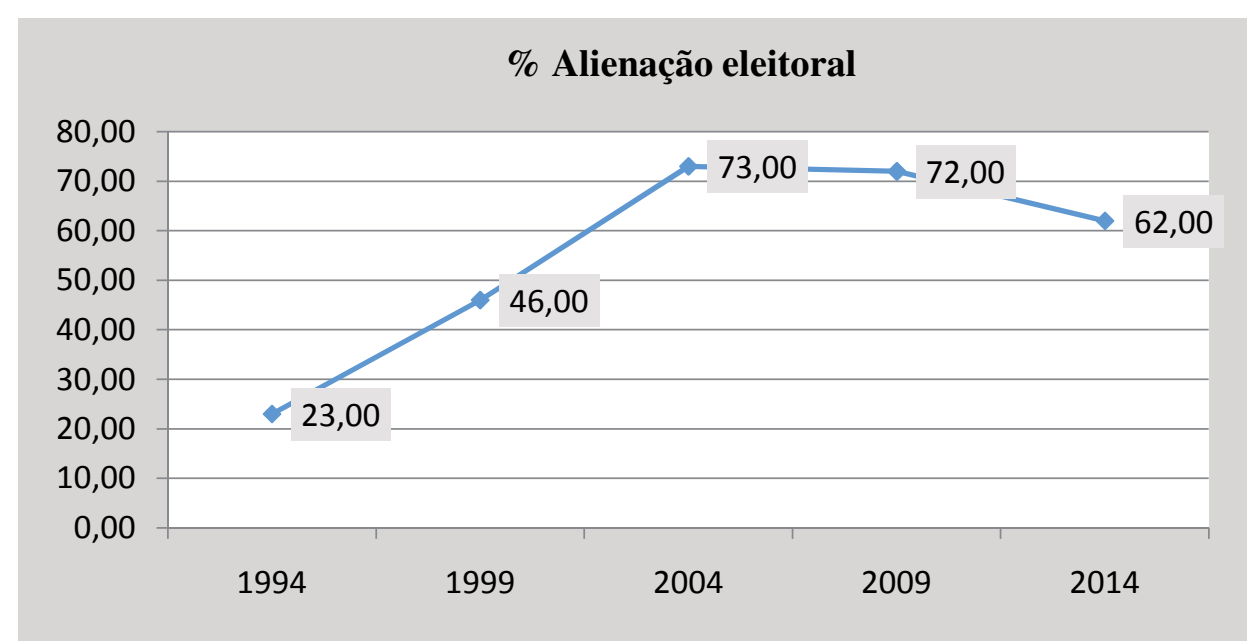

Fonte: CNE. Elaborado pelo autor (2016)

Observe que em Moçambique há uma tendência de crescimento oscilatório do nível de alienação eleitoral em relação à participação eleitoral. Para Ramos (2004a, 2006b) são vários motivos que influenciam o eleitor a alienar seu voto desde os fatores políticos, ecológicos e socioeconômicos. Todos estes fatores podem ser mobilizados para explicar a situação moçambicana, mas, para efeito deste artigo priorizamos a explicação socioeconômica, principalmente para as últimas eleições.

Alguns estudos levado acabo por Mazula (1995), Sitoe (2006) e Brito (2010), consideram que as organizações internacionais, bem como as nacionais ${ }^{20}$, foram importantes para que as primeiras, bem como as segundas eleições em Moçambique, fossem realizadas em um ambiente cordial, o que permitiria o seu sucesso. Para estes autores, as primeiras e as segundas eleições multipartidárias em Moçambique eram vistas, não só como uma mudança da conjuntura política e social, mas, também, como um meio de pacificação do país e consolidação dos acordos de paz celebrados em Roma no ano de 1992. Por esta razão, motivados por um clima de pacificação, o eleitorado demonstrou nas urnas sua concordância com esta situação e, por este motivo, o nível de alienação foi muito pouco significativo em relação as outras eleições, como podemos ver no gráfico acima.

De acordo com Figueiredo (1991), os indivíduos participam no ato eleitoral, quando suas ações são compreendidas por elas mesmas e têm a capacidade de produzir resultados

\footnotetext{
${ }^{19}$ A percentagem da abstenção foi calculada tendo em conta o número total de votantes e a percentagem de voto branco e nulo foi calculada de acordo com os votos contidos na urna.

${ }^{20}$ Programas de educação cívica do STAE e CNE; de algumas ONG's como AWEPA, NDI, Fundação Friedrich Ebert, CARITAS; PNUD; ONUMOZ; Santo Egídio; National Democratic Institute; SARDC, CSC, ONU.
} 
desejados. Ou seja, a alienação eleitoral tende a ser maior quando o nosso voto nas eleições anteriores não teve nenhum impacto na nossa vida. No contexto moçambicano pósdemocratização, nota-se um maior nível de alienação eleitoral em relação ao nível de participação eleitoral desde 2004 nas eleições legislativas.

\section{Influência da pobreza na alienação eleitoral nas eleições legislativas em Moçambique}

Para Santos (1987) a abstenção, bem como os votos nulos e brancos, está associada às condições socioeconômicas dos indivíduos, privilegiando, sobretudo, o aspecto educacional e a renda. A escolarização e a renda têm sido apontadas como fatores que predispõe favoravelmente o indivíduo para a participação política. Nas eleições legislativas de 2009 e 2014 em Moçambique o nível de pobreza reduziu e ao mesmo tempo a alienação eleitoral também sofreu uma ligeira redução, conforme ilustra o Gráfico 3. Podemos assim afirmar que a melhoria de condições de vida (redução da pobreza), bem como o nível elevado de escolaridade, permitiu com que os níveis de alienação eleitoral fossem reduzidos de forma significativa. Estas explicações já tinham sido fundamentadas teoricamente por Santos (1987), que mostra que os níveis de escolaridade e a redução da pobreza são elementos chave para explicar a variação e a redução dos índices de alienação.

A visão econômica do comportamento eleitoral é sustentada, principalmente, pela intrínseca ligação existente entre as condições socioeconômicas, que se encontra aliada na possibilidade dos representantes eleitos serem responsabilizados pelo crescimento e desenvolvimento socioeconômico dos representados (MARTINS, 2010). Desta forma, podemos considerar que o fator econômico influencia na maior ou menor alienação eleitoral, no âmbito da escolha dos representantes, nas eleições legislativas em Moçambique, conforme observaremos no Gráfico 3: 
Gráfico 3: Relação entre a pobreza e alienação eleitoral nas eleições legislativas, em Moçambique, entre 1994 a 2014

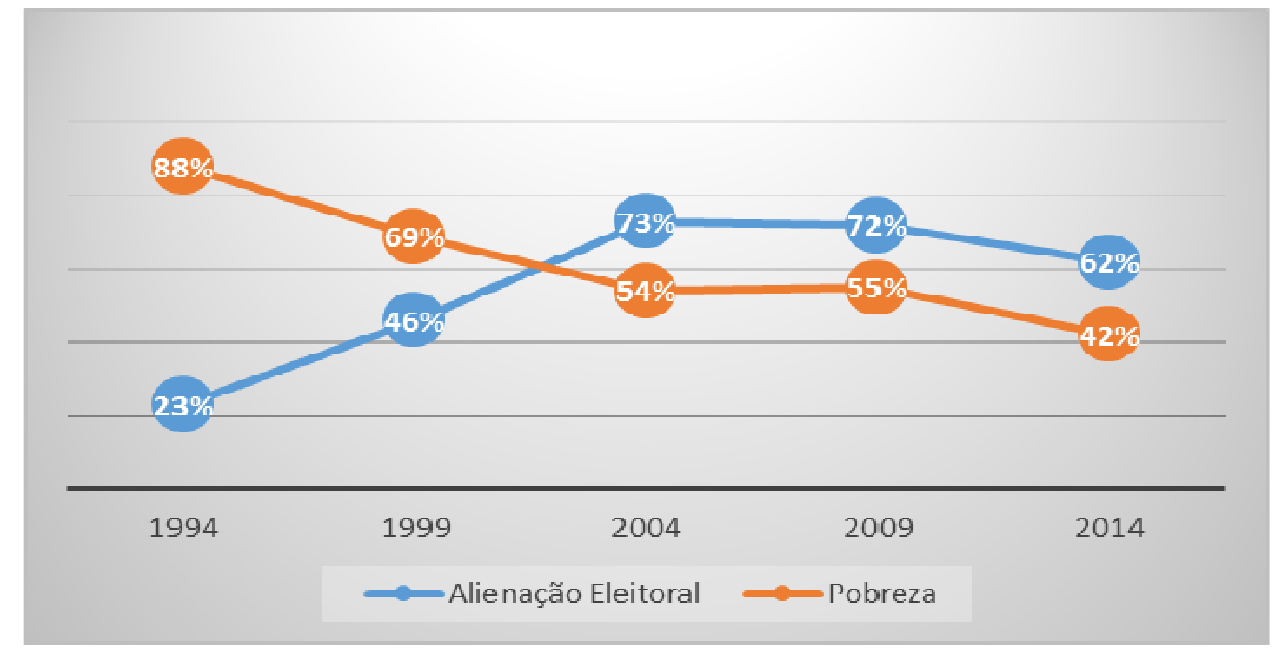

Fonte: CNE e MPD - INE-2013 Elaborado pelo autor (2016)

O fenômeno da alienação eleitoral em Moçambique encontra-se dividido em dois momentos, sendo o primeiro, que vai de 1994 a 1999, onde este fenômeno é relativamente baixo. Mesmo tendo a pobreza em níveis alarmantes, neste primeiro momento os eleitores afluíram em massa nas urnas com vistas a efetivar o processo de acordos de paz que passava por meio de realização das primeiras eleições multipartidárias, bem como na expectativa de ver suas condições melhorarem. No segundo momento, que parte de 2004 até as últimas eleições em 2014, podemos notar uma racionalidade do eleitor, que vendo suas condições não melhorarem, opta por alienar seu voto.

Esses resultados permitem ilustrar até que ponto a pobreza é um elemento crucial na participação política no geral e, em particular, nas eleições. Para Santos (1987) esse exercício é, em parte, condicionado pelo acesso às cabines de votação, extensão territorial e pelo grau de urbanização que representam custo de deslocamento do potencial eleitor, mas fatores socioeconômicos também influenciam significativamente na alienação eleitoral.

Podemos compreender, a partir do Gráfico 3, que, apesar do nível acentuado da pobreza, 88\% em 1994, a alienação eleitoral em Moçambique foi de 23\%. Isto deveu-se a mudança da conjuntura política nacional, com a implementação do sistema multipartidário e com consequente realização das primeiras eleições em 1994, aliado a um clima de democratização do país e fim da guerra civil. Esta situação fez com que o comportamento alienado fosse baixo, mesmo tendo o nível de pobreza extrema. Teóricos como Mazula (1995), Maia (1995), Namburete (1995), Brito (1995) e Sitoe (2006) afirmam que a 
comunidade internacional, bem como os lideres tradicionais, os agentes de educação cívica e as instituições governamentais, tiveram um papel preponderante para a maior afluência dos eleitores nas primeiras eleições. Para esta interpretação, o que alimentou a elevada participação foi a crença que o voto de cada cidadão poderia mudar o futuro de Moçambique. Assim, o conjunto do eleitorado via esse processo como um meio de melhoria das suas condições de vidas afetadas pela guerra civil.

Em 1999 é possível perceber como os eleitores ativos, em tese devido a não melhoria das suas condições de vida, começam a alienar o seu voto de forma gradual, onde podemos confirmaram um aumento de $100 \%$ de eleitores alienados em relação às eleições de 1994, passando deste modo dos $23 \%$ para $46 \%$, com o nível de pobreza a manter-se ainda elevado em 69\%. Desta forma, podemos perceber que em relação a 1994, a pobreza foi reduzida em $19 \%$, mas os eleitores que não sentiram o impacto da redução da pobreza nas suas vidas foram os que alienaram seus votos, pois, como referenciado por Martins (2010), Santos (1987), Figueiredo (2008) e Downs (1999), tais eleitores tendem a escolher seus representantes em função das melhorias das condições que se fizeram sentir na última vez em que exerceu seu dever cívico. Nota-se em 1999 uma gradual relação entre o nível de pobreza e o aumento de eleitores alienados nas eleições legislativas em Moçambique.

Em 2004 e 2009 a alienação eleitoral nas eleições legislativas foi de 73\% e 72\% respectivamente. Esse aumento considerável deveu-se ao nível de pobreza que ainda se situa acima dos 50\%, sendo que em 2004 a pobreza era de 54\% e em 2009 a pobreza era de 55\%. Nota-se uma subida insignificante da pobreza em 2009 em relação a 2004, contudo, apesar da pobreza ter reduzido em $15 \%$ em relação a 1999, ainda continua alto o nível, o que poderá ter levado os eleitores a alienarem seu voto, pois as suas condições de vida não terão melhorado de forma significante. Estudos desenvolvidos por Santos (1987), Lima (1990), Nicolau (2003) e Silva (2013), alegam que a taxa de alienação eleitoral tem como um dos fatores determinantes o retorno esperado da participação eleitoral anterior, pois o eleitor encontra-se numa relação de custo-benefício no momento de exercer seu voto, sendo a melhoria das condições socioeconômicas um fator que predispõe favoravelmente o indivíduo a participar nas eleições.

Em relação ao período de 2014, podemos notar que, por um lado, temos uma redução da pobreza para o nível inferior a $50 \%$, e, por outro lado, temos uma redução do comportamento alienado dos eleitores ativos. Contudo, notamos no Gráfico 3 que o nível de pobreza reduziu num percentual de $13 \%$ em relação ao período de 2009 , passando desta forma 
a se situar em $42 \%$, e, ao mesmo tempo, notamos uma redução do comportamento alienado em $10 \%$ em relação a 2009, ou seja, a melhoria de condições de vida de alguns eleitores ativos possibilitou, em tese, a redução do comportamento alienado do eleitor. Desta forma, notamos aqui que a melhoria das condições socioeconômicas pode influenciar na alienação eleitor. Esta ideia também é sustentada por autores como Santos (1987), Key (1966), Figueiredo (2008), Borba (2008) e Silva (2013), na qual as pessoas tendem a recorrer à alienação eleitoral dependendo das condições socioeconômicas, bem como a insatisfação do eleitor ativo em relação ao representante (candidato ou partido). Sendo assim, podemos afirmar que a pobreza é um fator importante para o comportamento alienado do eleitor.

\section{Considerações finais}

Este artigo procurou analisar quais fatores têm possibilitado a expansão da alienação eleitoral em Moçambique pós-democratização, concretamente nas eleições legislativas. A motivação principal para realização deste estudo foi o crescimento significativo da alienação eleitoral no cenário das eleições legislativas no país que, apesar de oscilar, tem sido maior que a participação eleitoral desde 2004.

Buscamos assim, na nossa analise, fazer uma relação entre a pobreza e o fenômeno da alienação eleitoral, com vistas a perceber até que ponto a pobreza estimula, retrai ou não afeta no nível de abstenção, votos nulos e brancos nas eleições legislativas em Moçambique. Partimos da ideia na qual quanto mais pobre o eleitorado, maior tende a ser a alienação eleitoral. Sendo assim, o comportamento eleitoral alienado pode ser explicado, em função do contexto socioeconômico, no qual as condições sociais objetivamente vividas explicam as atitudes e o comportamento eleitoral dos eleitores ativos.

Partimos da ideia de que o voto implica uma escolha, no processo de adesão à participação eleitoral, onde o contexto socioeconômico no qual os indivíduos estão inseridos pode determinar uma maior ou menor adesão ou o posicionamento político do eleitor. Os resultados da pesquisa sustentam que as condições socioeconômicas, concretamente a pobreza, explicam, em parte, o fenômeno da alienação eleitoral, embora existam outros fatores que influenciam este fenômeno da alienação para cada eleição.

Portanto, fica claro que nas eleições legislativas do período de 1994 a 2014, a variável estabelecida para este trabalho não é a única possível e tão pouco, por si só, explica as taxas de alienação eleitoral. O que se procurou demonstrar é que a pobreza é um dos fatores chave 
para explicar a manifestação da alienação eleitoral por parte dos eleitores ativos ao longo das eleições legislativas em Moçambique, num cenário de voto facultativo.

\section{Referências}

ALDRICH, John. H. Rational choice and turnout. American Journal of Political Science, vol.37, n.1, 1993.

ALMOND, G. \& VERBA, S. The civic culture: political attitudes and democracy in five nations. Princeton: Princeton University Press, 1963.

BORBA, Julian. As bases sociais e atitudinais da alienação eleitoral no Brasil. In: Debates, v. 2, p. 134-157, 2008.

COSTA, H. de O. Democracia e representação política no Brasil: uma análise das eleições presidenciais (1989-2002). Porto Alegre: Sulina. Natal: Ed. UFRN, 2007.

DE BRITO, L. Sobre a barreira dos $5 \%$ e do método de conversão dos votos em Mandatos, EISA Electoral Institute of Southern África, Maputo, 2005.

. "O Comportamento Eleitoral nas Primeiras Eleições Multipartidárias em Moçambique". In MAZULA, Brazão (org.), Moçambique, Eleições, Democracia e Desenvolvimento. Maputo, 1995, p.473.

O sistema eleitoral:Uma dimensão crítica da representação política em Moçambique, IESE, Maputo, 2010.

DOWNS, A. Uma Teoria Econômica da Democracia. São Paulo: Edusp, 1999.

DUCH, R.M., \& STEVENSON, R.T. The Economic Vote: How Political and Economic Institutions Condition Election Results. New York: Cambridge University Press, 2008.

FILGUEIRAS, Fernando. Corrupção, Democracia e Legitimidade. Belo Horizonte: Editora da UFMG, 2008.

FIGUEIREDO, Marcus. A decisão do Voto: Democracia e Racionalidade. São Paulo. Editora Sumaré, ANPOCS, 1991

GOODMAN, Saul, and KRAMER, Gerald H. Comment on Arcelus and Meltzer, the effect of aggregate economic conditions on congressional elections. American Political Science Review, 69:1255-1265, 1975.

LEWIS-BECK, M.S. Economics and Elections: The Major Western Democracies. Ann Arbor: University of Michigan Press, 1988. 
LIMA JÚNIOR, O. B. A alienação eleitoral e seus determinantes. Revista Brasileira de Ciências Sociais, n. 14 anos 5, 1990.

LIPSET, Seymour. O homem político. Rio de Janeiro: Zahar Editora, 1967.

MARCONI, Marina \& LAKATOS, Eva. Metodologias do Trabalho Cientifico: Procedimentos básicos, pesquisa bibliográfica, projeto e relatório publicações e trabalhos científicos. $7^{\text {a }}$ Ed. $3^{\text {a }}$ Reimpressão. São Paulo Atlas. 2009.

MAIA, Juarez de. "O projecto de Educação Cívica no Processo Eleitoral Moçambicano”. In MAZULA, Brazão (org.), ed. Moçambique, Eleições, Democracia e Desenvolvimento. Maputo, 1995, p.159.

MAZULA, Brazão. “As Eleições Moçambicanas: Uma trajectória da Paz e da Democracia”. In MAZULA, Brazão (org.), ed. Moçambique, Eleições, Democracia e Desenvolvimento. Maputo, 1995, p.25.

. "Democracia, Eleições e Medias: O caso das Eleições de 2004". In MAZULA, Brazão (org.), Moçambique, Eleições Gerais 2004: um olhar do Observatório Eleitoral. Maputo, Imprensa Universitária 2006.

MONROE, K. R. Presidential Popularity and the Economy. New York: Praeger, 1984.

NAMBURETE, Eduardo. “A imprensa no processo de democratização de Moçambique”. In MAZULA, Brazão (org.). Moçambique, Eleições, Democracia e Desenvolvimento. Maputo, 1995, p.231.

NICOLAU, Jairo. A participação eleitoral no Brasil. Working Paper Series, University of Oxford Centre for Brazilian Studies, 2002. Disponível em: <http://www.brazil.ox.ac.uk/_data/assets/pdf_file/0018/9405/Nicolau26.pdf $>$, acessado em Maio de 2016.

. “A participação eleitoral no Brasil”. In VIANNA, Luiz Werneck (org). A Democracia e os três poderes no Brasil. Editora UFMG/Iuperj/Ucam/ Fapesp, 2003.

RAMOS, P. N. Alheamento eleitoral: reflexões sobre o significado de votos em branco, votos nulos e abstenções na teoria política contemporânea. Mediações, Brasília, 14(1), 2009, p. 170199.

Partidos aliados em eleição presidencial no Brasil: análise das coligações vencedoras em 1994, 1998 e 2002. Dissertação (Mestrado em Ciência Política), Universidade de Brasília, Brasília, 2004.

. Alheamento eleitoral: legitimidade democrática e o significado de votos em branco, votos nulos e abstenções. Mimeo, Brasília, 2006. 
PNUD. Atlas do Desenvolvimento Humano em Moçambique. Disponível em <http://www.pnud.org.mz>. Acesso em: Abril de 2016.

SANTOS, W. G. Crise e castigo: partidos e generais na política brasileira. Rio de Janeiro: Editora Vértice/IUPERJ, 1987.

SILVA, R.; GIMENES, E. R.; BORBA, J.; RIBEIRO, E. A. Votos Brancos e nulos no Brasil: bases cognitivas e atitudinais. Teoria \& Pesquisa, 23(2), 2014, p. 58-75.

SITOE, Eduardo, Abstenções: "Perspectivas e Desafios para a Consolidação da Democracia". In MAZULA, Brazão (org.). Moçambique: Eleições Gerais 2004, Um olhar do Observatório Eleitoral, Maputo, 2006, p.156.

TERENCIANO, F., SOUZA, C. Competição Política e Geografia Eleitoral em Moçambique (1994-2014). Dissertação (Mestrado em Ciência Política), IFCH, UFPA, Belém, 2016.

VITULLO, Gabriel. Reflexiones sobre la calidad de la democracia brasileña. Nuestro Mondo. n.1, Buenos Aires, Argentina, 2001.

"Participación Electoral, Comportamiento político e Desetruturación Social em Argentina e Brasil". In: BETINA, L (org.). Crisis y conflictos em capitalismo latinoamericano. Lecturas Politicas. Buenos Aires: CLACSO, 2002.

KIEWIET, D. Roderick. Macroeconomics \& Micropolitics: the Electoral Effects of Economic Issues. Chicago, Illinois: University of Chicago Press, 1983.

KINDER, Donald R., ADAMS, Gordon S. \& GROKE, Paul W. Economics and Politics in the 1984 American Presidential Election. American Journal of Political Science, 33:491-515, 1989.

KINZO, Maria D’Alva Gil. Os partidos no eleitorado: percepção pública e laços partidários no Brasil. Revista Brasileira de Ciências Sociais, São Paulo, v.20, n.57, fev. 2005.

KEY, V.O. The Responsible Electorate: Rationality in Presidential Voting 1936-1960. Cambridge, Mass: Harvard University Press, 1966.

Recebido em 20 de agosto de 2016.

Aprovado em 16 de novembro de 2016. 